\title{
A Aplicação de Salvaguardas Gerais no Contexto de Processos de Integração Regional
}

\author{
Adriana S. Benatti(
}

\begin{abstract}
Resumo: $\mathrm{O}$ artigo trata da utilização das salvaguardas gerais como mecanismo de defesa comercial no contexto de processos de integração econômica regional. As observações e conclusões consideram as medidas aplicadas pelo bloco integrado (ou por um dos membros constitutivos) em relação a terceiros mercados, ou seja, como política de comércio ex terior em relação a terceiros mercados.
\end{abstract}

Palavras-chave: Salvaguardas Gerais, Processos de Integração Econômica Regional, Política de Comércio Exterior.

\begin{abstract}
The subject of this paper is the application of general safeguards as a trade remedy mechanism in the context of regional economic integration processes. The observations and conclusions consider the measures applied by the countries as a unit (or one of the members) against third markets, in other words, as foreign trade politic considering third markets.
\end{abstract}

Keywords: General Safeguards, Regional Economic Integration Processes, Foreign Trade Politic.

(*) Aluna do Programa de Pós-Graduação em Integração da América Latina - PROLAM - Universidade de São Paulo (USP).E-mail: adriana.benatti@gmail.com. Recebido em: 4.9.08 e aceito em: 20.11.08. 


\section{INTRODUÇÃo}

Quando da criação do General Agreement on Tariffs and Trade — GATT, em 1947, concomitantemente à elaboração de mecanismos de regulação do comércio internacional, com o objetivo de potencializar e incrementar as trocas entre as nações, possibilitando um crescimento pautado no liberalismo econômico e na eliminação das distorções e restrições entre os membros, previu-se, fundamentalmente, três instrumentos de defesa comercial, para coibir práticas desleais entre os países envolvidos. Foram eles: Medidas Compensatórias, Direitos Antidumping e Salvaguardas.

As Medidas Compensatórias teriam por finalidade compensar o subsídio concedido no país exportador, direta ou indiretamente, à fabricação, produção, exportação ou transporte de qualquer produto cujas importações viessem causar dano à indústria de terceiros países. Seriam implementadas por meio de alíquotas ad valorem ou específicas, fixas ou variáveis, ou pela conjugação de ambas.

Os Direitos Antidumping materializar-se-iam por meio da aplicação de alíquotas específicas, ad valorem ou da combinação de ambas, nos casos em que fosse constatada a prática de dumping por parte dos produtores do país exportador, com o intuito de evitar ou remediar os danos materiais provocados aos produtores do país importador. Essa prática seria identificada nos casos em que uma empresa exportasse certa mercadoria a preço inferior àquele praticado para produto similar nas vendas no seu mercado interno.

As Salvaguardas, por sua vez, seriam adotadas pelos governos para resguardar temporariamente a indústria doméstica das importações crescentes, independentemente de sua procedência, que estivessem causando ou que ameaçassem causar prejuízo grave ${ }^{(1)}$ à indústria nacional. Em outras palavras, o objetivo desta medida seria fornecer à indústria doméstica um breathing space, ou um período de tempo, para que ela pudesse se reestruturar, tornando o produto nacional competitivo frente ao importado.

De acordo com Thorstensen (2003), o tema Salvaguardas foi introduzido no GATT desde a sua criação, por meio do artigo XIX. Todavia, esse dispositivo veio apenas reproduzir a legislação norte-americana sobre o tema. A inexistência de regulamentação deste artigo dava margem a dificuldades de interpretação e incertezas em sua aplicação, permitindo que os países recorressem às medidas da chamada gray área (ou área cinzenta), especialmente aos acordos de restrição voluntária às exportações — os quais eram, em verdade, imposições baseadas em ameaças ou retaliações dos países desenvolvidos e com maior poder de barganha sobre os exportadores subdesenvolvidos. A preocupação concernente à área cinzenta levou à inclusão da premência de um código sobre Salvaguardas na Declaração Ministerial que precedeu a Rodada Tóquio do GATT, em 1973. (THORSTENSEN, 2003, p. 151)

Diante do insucesso em lograr um Acordo ainda durante a Rodada Tóquio, regulamentou-se, já na Rodada Uruguai, 1986-1994, a aplicação das Salvaguardas previstas no art. XIX do GATT como medidas de proteção, bem como se proibiu o uso de acordos de restrição às exportações, que resultavam de acordos bilaterais administrados entre um

(1) Entendido como enfraquecimento geral e significativo das atividades de determinado setor da economia. 
país importador e outro exportador para que fosse evitado o uso de medidas de proteção como Antidumping e Direitos Compensatórios. (THORSTENSEN, 2003, p. 151)

Firmou-se, então, o chamado Acordo sobre Salvaguardas ${ }^{(2)}$, apresentando definições mais claras acerca dos conceitos de aumento de importações, prejuízo grave e indústria nacional. Adicionalmente, ele instituiu a exigência de investigações prévias, estabeleceu prazo máximo para a vigência das medidas, conferiu tratamento favorável aos países em desenvolvimento, proibiu a adoção das restrições voluntárias às exportações e outros acordos de organização de mercado, disciplinou os procedimentos de notificação e consulta entre os membros e criou o Comitê sobre Salvaguardas. Convencionou-se, por fim, que tal Acordo trataria das Salvaguardas Gerais, excetuando-se as de caráter Transitório e as Especiais. (BROGINI, 2002, p. 255)

Como colocaram Brogini e Goyos Jr., as Salvaguardas Transitórias seriam aplicáveis aos produtos têxteis e de vestuário não incorporados ao GATT 1994 e para os quais haveria sido reservado o direito dos países recorrerem aos termos do Acordo sobre Têxteis e Vestuário $^{(3)}$. Esse acordo estabeleceu um regime de exceção para a adequação do setor às novas regras do comércio internacional e proibiu a aplicação do Acordo sobre Salvaguardas às Salvaguardas Transitórias. As Salvaguardas Especiais, por sua vez, foram previstas no art. $5^{\circ}$ do Acordo sobre Agricultura da OMC e podem ser implementadas contra as importações de produtos agropecuários abrangidos pelo Acordo e indicados como produto objeto de concessão, existindo sobre ele compromissos de acesso a mercado. (BROGINI, 2002, p. 206-261; GOYOS JUNIOR, 2003, p. 99-100)

Cabe destacar alguns dos principais aspectos de distinção entre as Salvaguardas Gerais e os Direitos Antidumping. Um deles seria que a aplicação do último não ocorre em resposta a práticas desleais de comércio, tais como o dumping, e sim por deficiências de competitividade da indústria nacional. Adicionalmente, as Salvaguardas restringem as importações provenientes de todas as origens, além de exigirem o comprometimento da indústria nacional, junto ao governo nacional aplicador da medida, em adotar um programa visando ao aprimoramento e ao incremento de competitividade - algo próximo a um programa de ajuste. (BARRAL, 2000, p. 140; BENKE, 2003, p. 6)

A despeito da existência de Salvaguardas Transitórias e Especiais, por razões de delimitação da abrangência da questão a ser abordada, este artigo limita-se a tratar das Salvaguardas Gerais no contexto de Processos de Integração Econômica Regional PIER. Ademais, as considerações expostas dizem respeito às Medidas de Salvaguarda aplicadas pelo bloco integrado (ou por um de seus membros constitutivos) em relação a terceiros mercados, e não intrabloco. Em outras palavras, a aplicação da medida será aqui tratada como política de comércio exterior do bloco ou de um de seus membros em relação a terceiros mercados.

O interesse pelo desenvolvimento do tema justifica-se pela importância crescente dos mecanismos de defesa comercial no sistema internacional e pelo incremento dos PIER,

(2) Internalizado pelo Brasil por meio do Decreto n. 1.355, de 30 de dezembro de 1994, e regulamentado pelos Decretos n. 1.488 , de 11 de maio de 1995 e n. 2.667 , de 10 de julho de 1998 .

(3) Assim como o Acordo sobre Salvaguardas, o Acordo sobre Têxteis e Vestuário foi instituído no âmbito da Organização Mundial do Comércio - OMC. 
os quais incitam o surgimento de questionamentos relativos à utilização desses instrumentos por membros de países que participem de iniciativas dessa monta.

Na primeira parte deste artigo, encontram-se algumas palavras acerca do conceito e da aplicação das Medidas de Salvaguarda, pautadas nas tratativas desenvolvidas junto à Organização Mundial do Comércio - OMC. Em seguida, breves colocações acerca dos PIER são realizadas para, finalmente, traçarem-se comentários e observações relativos à utilização do instrumento por participantes de processos desse tipo.

\section{Medida de SALVAguarda Geral: CONCEITO E APLiCAÇ̃̃o}

Com o intuito de contextualizar o instrumento de defesa comercial, discorrer-se-á brevemente acerca do conceito e da aplicação das Salvaguardas Gerais. Tais medidas são utilizadas em ocasiões em que o aumento da importação de determinado produto cause ou ameace causar prejuízo grave aos produtores domésticos em determinado mercado nacional, sendo aplicadas com a finalidade de aumentar temporariamente a proteção da indústria doméstica para que ela ajuste e recupere sua competitividade.

Elas têm caráter de urgência, temporalidade e são empregadas proporcionalmente ao necessário para prevenir ou remediar o prejuízo grave e facilitar o ajustamento da indústria nacional. (BROGINI, 2002, p. 252)

Pinheiro e Guedes destacam que as Salvaguardas seriam úteis, em uma primeira análise, aos países de tradição protecionista que estão na fase de abertura comercial, já que elas permitem que as indústrias locais se adaptem à concorrência externa; aos setores que perderam competitividade em âmbito internacional, vez que as Salvaguardas podem evitar o desemprego em massa e possibilitar que a mão de obra se adapte e consiga ser transferida para outro setor da economia; e aos países com problemas de balanço de pagamentos, cabendo sim a implementação de Salvaguardas generalizadas. (PINHEIRO, GUEDES, 1998, p. 330)

A aplicabilidade da medida estende-se a todos os produtos industrializados e também aos produtos têxteis e agropecuários já integrados ao GATT 1994. A efetiva implementação, dada pelo estabelecimento de quotas às importações ou pela elevação de tarifas ${ }^{(4)}$, deve ser precedida por investigação pública, cabendo à autoridade competente do país prejudicado constatar a ocorrência do aumento das importações, de prejuízo grave ou ameaça de prejuízo à sua indústria e de nexo causal entre tais elementos.

Na investigação para determinar se um aumento das importações causou, ou ameaça, causar grave prejuízo à indústria doméstica, as autoridades devem avaliar todos os fatores relevantes de natureza objetiva e quantificável que tenham relação com a situação daquela indústria, em particular: a taxa e o valor do aumento das importações, em termos relativos e absolutos, a participação no mercado doméstico tomada pela importação, as mudanças nos níveis de venda, produção, produtividade, capacidade utilizada, lucros e perdas e emprego". (THORSTENSEN, 2003, p. 152)

(4) Alíquotas essas que podem ser ad valorem, específicas ou se configurarem na conjugação de ambas, conforme mencionado oportunamente. 
Dentre as obrigações pertinentes àquele que se pretende aplicador de Salvaguarda, cabe manter um nível de concessões com os países exportadores afetados pela medida. Para tanto, permite-se o estabelecimento de acordos que prevejam a maneira mais adequada de compensação comercial pelos efeitos indesejados da aplicação do referido instrumento. Vale ressaltar que, na eventualidade de não haver acordo, os países exportadores podem suspender concessões ou outras obrigações substancialmente equivalentes em relação ao país importador.

Outra obrigação inerente ao interessado na aplicação está relacionada às notificações e consultas ${ }^{(5)}$. As notificações são dirigidas ao Comitê de Salvaguardas da OMC e devem ocorrer quando do início de um processo de investigação, da constatação de prejuízo ou ameaça de prejuízo à indústria nacional provocado pelo aumento das importações e da decisão pela aplicação ou prorrogação de uma Salvaguarda. As consultas, por sua vez, devem ocorrer antes da aplicação da medida ${ }^{(6)}$.

Finalmente, a aplicação de uma Salvaguarda deve se basear no princípio de não seletividade, o qual estabelece que a medida será aplicada ao produto importado, independentemente de sua procedência ${ }^{(7)}$. Esse princípio, derivado do Princípio da Nação Mais Favorecida, é um dos pilares do Acordo sobre Salvaguardas e já havia sido previsto no art. XIX do GATT 1947. É nesse contexto que se encaixa a discussão a qual o presente artigo pretende explanar ${ }^{(8)}$.

\section{Breves PALAVRAS ACERCA doS PROCESSOS DE INTEGRAÇÃo REGIONAL}

As iniciativas de integração econômica regional são, geralmente, motivadas pelo desejo dos países envolvidos em aumentar a articulação de suas cadeias produtivas, elevar o comércio com os demais parceiros, ampliar a escala e a produtividade da indústria doméstica e incrementar suas economias nacionais. Seria possível dizer que a integração econômica regional, se bem constituída, possibilitaria a ampliação de mercados, a especialização regional (ideia de vantagens comparativas), maior eficiência na industrialização, a ampliação das exportações industriais e a ampliação do poder de barganha no cenário internacional (por meio da criação de infraestrutura e instituições), dentre outros benefícios.

A integração teria início a partir da eliminação de tarifas de importação intrabloco (livre-circulação de bens), passando pela constituição de uma tarifa externa comum e pela coordenação e confecção de políticas macroeconômicas, contando com a livre mobilidade

(5) Conforme art. 12 do Acordo sobre Salvaguardas.

(6) Como assinala Brogini, as notificações têm por finalidade permitir que os países defendam seus interesses e solicitem a realização de consultas, além de assegurar a compatibilidade das medidas e o seu efetivo controle. As consultas têm por objetivo examinar as informações fornecidas nas notificações, bem como possibilitar a realização de um entendimento prévio acerca da compensação estipulada no art. 8.1 do Acordo sobre Salvaguardas. (BROGINI, 2000, p. 37-39)

(7) Nos termos do art. 2.2 do Acordo sobre Salvaguardas.

(8) Interessante ressaltar que o art. 9.1 do Acordo sobre Salvaguardas, visando a proporcionar um tratamento mais favorável aos países em desenvolvimento, estabelece uma exceção ao princípio da não seletividade: "não se aplicarão medidas de salvaguarda contra produto procedente de país em desenvolvimento quando a parcela que lhe corresponda nas importações efetuadas pelo Membro importador do produto considerado não for superior a três por cento, contanto que os países em desenvolvimento Membros com participação nas importações inferior a três por cento não representem em conjunto mais de nove por cento das importações totais do produto em questão". 
de bens, pessoas e serviços. Em alguns casos chegaria mesmo à adoção de uma moeda única. $\mathrm{O}$ avanço dos processos de integração implicaria, consequentemente, na busca pela estabilidade cambial do bloco de países, na harmonização de legislações entre os membros e na coordenação das políticas macroeconômicas, entre outros aspectos.

A observação relativa à boa/plena constituição da integração econômica regional é válida justamente pelo fato de ser ela o fator condicionante do sucesso do avanço das economias e da concretização ou não da interdependência entre elas. Raul Prebisch, pensando na constituição de um Mercado Comum na América Latina, assinalou, ainda em 1959, que:

O desenvolvimento das exportações industriais para o resto do mundo poderá ser uma das consequências derivadas do mercado comum, ainda que não constitua seu objetivo primordial, direto e imediato. Esse objetivo é duplo: (a) desenvolver intensamente as exportações industriais de cada um dos países latino-americanos para os demais; e (b) dar um forte estímulo ao comércio tradicional de produtos primários, a fim de manter dentro dos limites de uma economicidade razoável a política nacional de substituição de importações. (...) O mercado comum lhe [a um país] dará (...) outra alternativa: desenvolver exportações industriais para os outros países da América Latina, a fim de adquirir neles os produtos que, de outro modo, ver-se-ia forçado a substituir. Dessa maneira, em vez de procurar implantar toda sorte de indústrias substitutivas, cada país poderá especializa-se naquelas que julgar mais convenientes, de acordo com seus recursos naturais, com aptidões de sua população e com as possibilidades de seu próprio mercado; e recorrerá a importações provenientes dos demais países latino-americanos para satisfazer outras necessidades de produtos industrializados que não tenham podido ser atendidas por importações do resto do mundo. (PREBISCH, 1959 in BIELSCHOWSKY, 2000, p. 361-362)

A princípio, os diferentes níveis do processo integracionista revelam o grau de interdependência e complementaridade das economias envolvidas ${ }^{(9)}$. Logicamente, devido à complexidade das questões a serem tratadas, nem sempre a denominação da etapa do processo corresponde por completo à situação de relacionamento e proximidade em que se encontram as economias. Costumeiramente, as iniciativas partem da criação de Zonas de Livre Comércio que, paulatinamente, caminham para Uniões Aduaneiras, Mercados Comuns e, no limite, Uniões Econômicas/Políticas.

Na Zona de Livre Comércio, tida como a primeira etapa do processo, os membros contam, basicamente, com a eliminação progressiva das tarifas de importação e das ditas barreiras não tarifárias entre os países, o que implica na livre circulação de bens industriais e não industriais. Na segunda etapa, quando da constituição de uma União Aduaneira, além da livre-circulação de bens, por conta do objetivo em estabelecer uma política comercial comum, adotam-se os mesmos patamares tarifários (adesão a uma tarifa externa comum, conhecida como TEC). A terceira etapa, o Mercado Comum, pressupondo já o estabelecimento dos aspectos característicos da etapa anterior, vem acrescentar ao relacionamento das

(9) A respeito do grau ou nível de integração entre os países, existem diferentes indicativos empíricos considerados pelos estudiosos como aspectos medidores, tais como os volumes de comércio ou a mobilidade de fatores. 
economias membro a livre circulação de pessoas e serviços. Por fim, a União Econômica/ Política, além das características do Mercado Comum, concede espaço à criação de uma moeda única ao bloco.

Considerando a constituição de Uniões Aduaneiras, Brogini assinalou que:

A integração de países para a formação de uma UA [União Aduaneira] não é de fato um processo simples. Além da vontade política, fator inicial, faz-se necessário que os países constitutivos se comprometam em harmonizar suas políticas que afetam o comércio internacional de bens, em tudo o que pode vir a atingir sua livre circulação: procedimentos aduaneiros, barreiras tarifárias e não tarifárias, comércio exterior, etc. Mas o fundamental neste processo é que os países constitutivos estabeleçam um cronograma de liberalização que possibilite sua realização equilibrada, tendo-se em vista especialmente os setores mais sensíveis de cada economia integrante, aqueles que reclamam maior tempo para ajustes a fim de poderem enfrentar a concorrência que resultará da livre-circulação de bens após a formação da UA. (BROGINI, 2002, p. 58-59)

Logicamente, esse raciocínio pode ser estendido para toda a evolução que segue a formação de Uniões Aduaneiras, a saber o Mercado Comum e a União Econômica/Política. Enfatiza-se que as motivações para a integração tendem a conduzir os países a patamares que atendam às suas expectativas. Em outras palavras, não necessariamente uma Zona de Livre Comércio alcançará o status de União Aduaneira se, já no primeiro estágio de aproximação, os membros tiverem obtido os benefícios econômicos/políticos/sociais esperados.

Assim, considerando ser o patamar do processo de integração um indicador importante a respeito do grau de proximidade e coordenação das economias envolvidas, em uma primeira abordagem alguns observadores poderiam afirmar que quanto mais alto o nível do processo, mais lógico seria trabalhar com investigações para a aplicação de Salvaguarda baseadas em análises do bloco, como um ente econômico único. Como veremos, entretanto, há alguns outros fatores a verificar.

É nesse contexto de intensificação e acirramento das trocas comerciais e de aproximação entre as economias integrantes que surge a questão da utilização de instrumentos de defesa comercial, especificadamente Salvaguardas Gerais, em relação a terceiros mercados.

\section{SALVAGUARDAS E PROCESSOS DE INTEGRAÇÃo REgIONAL}

Com o objetivo de discorrer a respeito dos aspectos relevantes acerca da utilização de Medidas de Salvaguarda por parte de membros de PIERs, as questões aqui levantadas serão ilustradas por meio de referências ao Painel solicitado pela Comunidade Europeia junto à $\mathrm{OMC}$ que tratou da imposição de Salvaguarda por parte da Argentina às importações de calçados ${ }^{(10)}$. Já de início, é importante dizer que, em diversos aspectos relativos ao

(10) Tal painel, adotado em 12 de janeiro de 2000, foi solicitado pela Comunidade Europeia e tratou de Medida Provisória e Medida Definitiva de Salvaguarda imposta pela Argentina nas importações de calçados. Como terceiras partes, participaram o Brasil, Indonésia, Paraguai, Uruguai e Estados Unidos (Consultar documento WT/DS121/AB/R, disponível em: <www.wto.org>). 
tema apresentado, não há consenso entre os estudiosos, tampouco entre os agentes de mercado e que, por essa razão, optou-se em apresentar as considerações feitas pelo Comitê analisador da OMC.

Essencialmente, três questões serão abordadas, a saber: (a) aplicação da Salvaguarda individual ou em bloco; (b) exclusão dos membros do bloco da incidência de quotas e sobretaxas concernentes à medida; e (c) utilização de dados econômico-comerciais do bloco nas investigações.

A primeira delas, remeter-se-ia à determinação do "agente implementador" da Salvaguarda. Considerando o disposto no art. 2.1 do Acordo sobre Salvaguardas referente às particularidades e individualidades de cada uma das economias envolvidas no PIER ${ }^{(11)}$, pode-se entender que um país-membro, partindo da identificação da necessidade da aplicação de Salvaguarda, contaria com a possibilidade de implementar unilateralmente a medida. Entretanto, considerando que a Salvaguarda pressupõe a existência de obstáculos à competitividade da indústria nacional (algo como uma "ineficiência"), seria logicamente razoável pensar em envolver os demais membros diante do pressuposto de que as economias são integradas e, portanto, as dificuldades de competitividade dizem respeito a todas. Deve-se, todavia, atentar para a constatação dos obstáculos comuns ao processo já que, considerando as deficiências inerentes à integração das cadeias produtivas, é possível que a justificativa para a aplicação da medida pelo bloco caia por terra. Uma outra dificuldade da atuação em bloco seria a necessária existência de instituições intergovernamentais bem articuladas e legitimadas para a boa coordenação e troca de informações entre os países interessados.

Esse apontamento surge no contexto do princípio de não seletividade, rogado pelo Acordo de Salvaguardas Gerais. Como quis Brogini, "Um outro ponto referente ao princípio da não seletividade diz respeito à sua aplicação ou não entre membros de acordo comercial regional (...). Ainda não existe consenso a respeito, mas a recomendação da OMC é de que deve haver um certo paralelismo entre as investigações e a aplicação das medidas, nos termos do art. $2.1 \mathrm{c} / \mathrm{c}$ art. 2.2, ambos do Acordo sobre Salvaguardas. Desse modo, e no mesmo sentido, se ao analisar as importações as autoridades competentes incluírem os produtos de todas as fontes, obrigatoriamente as medidas devem ser aplicadas contra todas elas." (BROGINI, 2002, p. 259)

Em relação a excluir os integrantes do PIER da sujeição às quotas e às sobretaxas concernentes ao instrumento, considerar-se-iam duas frentes. Uma primeira seria aquela derivada de uma aplicação em bloco e a outra, de uma aplicação individual.

Pela lógica, a aplicação da Salvaguarda por parte do bloco só faria sentido se o mesmo, nas suas relações internas - ditas intrabloco - , fosse excluído das quotas e das sobretaxas, já que a demanda pelo instrumento de defesa comercial partiu dele como um todo, como um agente único.

(11) "A Member may apply a safeguard measure to a product only if that Member has determined, pursuant to the provisions set out below, that such product is being imported into its territory in such increased quantities, absolute or relative to domestic production, and under such conditions as to cause or threaten to cause serious injury to the domestic industry that produces like or directly competitive products." (Trecho do Acordo sobre Salvaguardas citado no documento WT/DS121/AB/R) 
No caso da aplicação individual, excluir os demais membros do PIER da aplicação das quotas e das sobretaxas infringiria diretamente o art. 2.2 do Acordo sobre Salvaguardas, o qual dispõe que "Safeguard measures shall be applied to a product being imported irrespective of its source". Entende-se que é necessário resguardar a economia nacional das importações de determinada mercadoria, independentemente de sua origem. No episódio das Salvaguardas argentinas contra as importações de calçados, o Comitê da OMC entendeu que: "a member-state-specific investigation that finds serious injury or threat thereof caused by imports from all sources cannot serve as a basis for imposing a safeguard measure on imports only from third-country sources of supply." (WT/DS121/AB/R)

No caso em análise, o Comitê entendeu que, no contexto da nota de rodapé do art. 2.1, a investigação de um Estado-membro na qual o prejuízo grave ou a ameaça de prejuízo grave está baseada nas importações provenientes de todas as origens conduziria à imposição de Salvaguardas com base no princípio de nação mais favorecida, contra todas as origens, tanto daquelas intrarregionais quanto das extrarregionais ${ }^{(12)}$.

Em suma:

On the basis of this reasoning, and on the facts of this case, we find that Argentina's investigation, which evaluated whether serious injury or the threat thereof was caused by imports from all sources, could only lead to the imposition of safeguard measures on imports from all sources. Therefore, we conclude that Argentina's investigation, in this case, cannot serve as a basis for excluding imports from other MERCOSUR member States from the application of the safeguard measures. (WT/DS121/AB/R)

E, em complemento, o Comitê assinalou que a Argentina aplicou a Medida de Salvaguarda após conduzir uma investigação a respeito dos produtos importados ao território argentino e dos efeitos dessas importações na indústria doméstica argentina. Assim, ao aplicar a Medida com base nesses parâmetros, o país também requereu, regido pelo art. 2.2, a aplicação desse instrumento às importações de todas as fontes, inclusive daquelas provenientes de outros membros do Mercosul.

Ao final, sob a luz do art. $2^{\circ}$ do Acordo sobre Salvaguardas e do art. XXIV do GATT, o Comitê concluiu que, no caso de uma União Aduaneira, a imposição de uma Salvaguarda somente a terceiros mercados fornecedores não se justifica com base em investigação conduzida por um único membro que tenha identificado prejuízo grave ou ameaça de prejuízo grave causado pelas importações provenientes de todas as origens, tanto de dentro quanto de fora do bloco. Manifestou que “(..) we make no ruling on whether, as a general principle, a member of a customs union can exclude other members of that customs union from the application of a safeguard measure." (WT/DS121/AB/R)

Assim, excetuar da aplicação das tarifas e do cumprimento das quotas os membros do bloco do qual o país interessado faz parte seria uma clara infração ao princípio de não

(12) No Documento WT/DS121/AB/R, assinala-se que: "(...) Thus, in the light of the context of the footnote to art. 2.1, a member-state-specific investigation in which serious injury or threat thereof is found based on imports from all sources could only lead to the imposition of safeguard measures on a MFN-basis against all sources of intra-regional as well as extraregional supply of a customs union”. (WT/DS121/AB/R) 
discriminação, fundamental nas tratativas desenvolvidas ao amparo da OMC. Ademais, ainda que se argumente que os próprios processos de integração regional são, por si só, uma exceção ao princípio da não discriminação — ou à cláusula da nação mais favorecida —, eles se justificam pelo art. XXIV, que trata exclusivamente da criação de áreas de preferências comerciais.

Outra questão alvo de dissenso refere-se à possibilidade do interessado na aplicação de Salvaguardas, sendo membro de um PIER, utilizar-se de dados e informações concernentes ao comércio do bloco, ou seja, considerar as transações comerciais realizadas por ele e pelas indústrias de seus parceiros para fins de investigação. Ora, se a indústria de certo país necessita de uma Salvaguarda dita "individual", ainda que ele seja parte de uma iniciativa de integração econômica, não se justifica o desejo de considerar os dados de outras indústrias além de suas fronteiras. Isso porque o prejuízo grave ou a ameaça de prejuízo grave, por ser constatado na indústria nacional do interessado, deve, logicamente, ser comprovado com dados que refletem única e exclusivamente a situação da mencionada indústria já que, teoricamente, não há prejuízo nas demais. Logo, conclui-se que as economias não estão satisfatoriamente integradas, já que se essa fosse uma verdade, o prejuízo seria identificado ao longo das cadeias produtivas do bloco.

No que concerne à utilização de dados, variáveis e constatações para fins de investigação, uma vez mais vem à tona a observação referente à caracterização do processo de integração. Se a integração for suficientemente coesa, faz sentido pensar em utilizar os dados de um país e estender a aplicação da medida para os demais, vez que, de tão conectadas, as economias se refletiriam e a utilização dos números de um membro tornar-se-ia, em verdade, uma amostragem fiel da situação vivenciada pelo bloco. Assim, partindo do pressuposto de que o patamar do processo de integração revele-se um indicador importante a respeito do grau de proximidade e coordenação das economias envolvidas, entende-se que quanto maior o nível do processo, mais sentido faz pensar em trabalhar com investigações baseadas em análises do bloco.

Entretanto, considerando todas as reais dificuldades da coordenação de informações e da imperfeita integração entre as cadeias produtivas inerentes ao PIER, o Comitê da OMC avaliou, durante a análise do painel aberto pela Comunidade Europeia em relação às medidas aplicadas pela Argentina às suas importações de calçados, que todos os aspectos relevantes da investigação devem ser conduzidos pelo interessado na aplicação do instrumento, com base no incremento das suas importações e do prejuízo grave ou ameaça de prejuízo grave em seu território ${ }^{(13)}$.

No que tange à aplicação em bloco, como o próprio Comitê assinalou, entende-se que quando uma União Aduaneira aplica uma Medida de Salvaguarda (como uma single unit),

(13) “Article 4.1(c) defines 'domestic industry' as meaning 'the producers as a whole of the like or directly competitive products operating within the territory of a Member (...)." (WT/DS121/AB/R)

"Taken together, the provisions of arts. 2.1 and 4.1(c) of the Agreement on Safeguards demonstrate that a Member of the WTO may only apply a safeguard measure after that Member has determined that a product is being imported into its territory in such increased quantities and under such conditions as to cause or threaten to cause serious injury to its domestic industry within its territory. According to arts. 2.1 and 4.1(c), therefore, all of the relevant aspects of a safeguard investigation must be conducted by the Member that ultimately applies the safeguard measure, on the basis of increased imports entering its territory and causing or threatening to cause serious injury to the domestic industry within its territory." (WT/DS121/AB/R) 
todas as variáveis necessárias à determinação do prejuízo grave devem estar baseadas nas condições verificadas na economia do bloco como um todo. E, da mesma forma, quando uma medida é aplicada por um Estado-membro, as variáveis a analisar quando das investigações prévias devem refletir as condições dessa economia e a medida deve se limitar a ela ${ }^{(14)}$.

\section{PerCePÇÕES}

Como apontou Thorstensen, um dos pontos levantados em meio às discussões do Comitê sobre Acordos Regionais de Comércio no que tange às implicações das questões sistêmicas aos acordos regionais para o comércio internacional, em especial nos aspectos que não estão definidos no art. XXIV do GATT, foi a aplicação de Medidas de Salvaguarda ou Direitos Antidumping entre os membros de um acordo regional.

A questão que se coloca é se uma vez estabelecido o acordo, as partes podem usar medidas de salvaguarda ou antidumping entre elas, ou se essa prática estaria violando o requisito de eliminação de direitos e outros regulamentos de restrição ao comércio. Além dessa questão, existe outra, relacionada à imposição de direitos antidumping ou de salvaguarda por apenas um membro do acordo contra um terceiro país, e se esse direito deve ser também assumido pelos demais membros do acordo contra terceiros países. (THORSTENSEN, 2003, p. 245)

No que se refere às três questões levantadas ao longo do texto, apreende-se que a aplicação de Salvaguarda por um bloco econômico é justificável apenas se a integração entre os membros constituintes for suficientemente coesa a ponto de fundamentar a análise das variáveis econômicas como um todo. Entretanto, considerando as dificuldades inerentes ao processo integracionista, em muitos casos, o caminho mais viável é a investigação e a adoção da Salvaguarda pelo Estado-membro interessado, de maneira individual. Exemplo disso foi o caso utilizado como modelo ilustrativo, no qual a Argentina, mesmo participando do Mercosul, aplicou Salvaguarda às suas importações de calçados, sem acarretar implicação alguma para os demais membros do bloco. Entende-se que, com base no princípio da não discriminação, os membros do PIER ao qual pertence o país interessado na Medida não devem ser excluídos do cumprimento da Salvaguarda.

Por um lado, algum observador poderia levantar o fato de que a exclusão do cumprimento às restrições impostas pelo Estado-membro aplicador da Salvaguarda seria oportuna já que a aplicação da medida aos demais constituintes do PIER contrariaria o propósito maior do bloco, qual seja, liberalizar a circulação de bens. Contudo, por outro, por identificar a necessidade de resguardar um setor de determinada economia da concorrência internacional - inclusive dos parceiros, já que as cadeias produtivas não se encontram

(14) "When a customs union applies a safeguard measure as a single unit, all the requirements for the determination of serious injury or threat thereof under this Agreement shall be based on the conditions existing in the customs union as a whole. When a safeguard measure is applied on behalf of a member State, all the requirements for the determination of serious injury or threat thereof shall be based on the conditions existing in that member State and the measure shall be limited to that member State. Nothing in this Agreement prejudges the interpretation of the relationship between art. XIX and paragraph 8 of Article XXIV of GATT 1994." (WT/DS121/AB/R) 
absolutamente integradas - e pelo princípio da não discriminação, avalia-se que não há justificativa para a exclusão dos demais membros do cumprimento à medida adotada.

Ademais, em consonância ao parecer do Comitê da OMC em relação ao Painel exposto, infere-se que a utilização dos dados dos membros do bloco, como um todo, deve se dar apenas nas ocasiões em que as investigações estiverem sendo levadas a cabo pelo bloco, como uma unidade. Se existe oportunidade para a instituição de Salvaguarda para o bloco, deve-se sim utilizar dados e variáveis de todos os membros, já que o prejuízo grave, ou a ameaça de prejuízo grave, foi constatado nas indústrias nacionais dos membros como um todo.

Pelo exposto, observou-se que a aplicação de Salvaguardas Gerais pelo Bloco só é possível a partir de Uniões Aduaneiras, já que em Zonas de Livre-Comércio, por definição, não haveria iniciativas para a coordenação de políticas comuns de comércio - apenas livre-circulação de bens. Brogini argumenta que "Sobre as regulamentações (...), imaginese que cada país constitutivo disponha de um sistema de nomenclaturas ou certificação de produtos absolutamente distinto, ou que as respectivas legislações aduaneiras contemplem critérios de isenções totalmente diferentes. Isto tudo reclama uma aproximação, uma busca de identidade, tanto no âmbito das normas materiais (definição de princípios e critérios de aplicação) quanto no da condução dos procedimentos tendentes à aplicação dessas normas, porque também são condições para a formação da UA [União Aduaneira] perfeita." (BROGINI, 2000: 74)

Avaliou-se, nesse sentido, que quanto mais avançado for um PIER, maior a probabilidade de aplicação de Salvaguarda "em bloco", exatamente pela já existência de tratativas comuns acerca de aspectos comerciais, inclusive da aplicação de instrumentos de defesa comercial, e pela necessária existência de instituições intergovernamentais ${ }^{(15)}$ necessárias ao desenrolar das investigações e à implementação e acompanhamento das quotas e sobretaxas.

Já a aplicação de Salvaguardas Gerais por um integrante de PIER (iniciativa individual), levada a cabo de maneira mais simplificada, não deveria considerar os dados do Bloco e tampouco excluir os demais membros da aplicação das quotas e sobretaxas concernentes à implementação da medida. Partindo do pressuposto que o país necessita de uma Salvaguarda para resguardar determinado setor de sua economia ainda não suficientemente competitivo em âmbito internacional, esse mesmo setor ainda não se encontra em condições para incrementar ou potencializar um processo de aproximação e interdependência com as economias do bloco.

O ideal, portanto, seria que o processo de interligação das cadeias produtivas do setor beneficiado pela Salvaguarda fosse inteiramente normalizado após o período de adaptação à concorrência. Vale ressaltar que a aplicação da Salvaguarda Geral não afetaria de maneira substancial o PIER em si, independentemente do seu grau de evolução, vez que o processo como um todo envolveria outros aspectos de relevância - tais como coordenação de políticas fiscais, monetárias, de legislações, etc. — que, no limite, sofreriam apenas efeitos indiretos e de baixo impacto das restrições comerciais impostas pela medida.

(15) Supranacionais, no limite da União Econômica/Política. 
Refletindo acerca do Mercosul, na atualidade, devido ao grau insatisfatório de integração entre as indústrias da região, não é possível fundamentar com facilidade a utilização de Salvaguarda pelo bloco. Entretanto, havendo insistência e empenho em desenvolver investigações para a verificação de prejuízo grave ou ameaça de prejuízo grave nas economias do bloco, reconhece-se que haveria uma importante aproximação entre os empresá-rios e os governos dos diferentes países, em resposta ao esforço de coordenação.

Deve-se considerar, todavia, que as probabilidades de encontrar interesses verdadeiramente comuns seriam baixas, já que tais interesses estariam condicionados ao sucesso da integração entre as economias. Isto posto, a dedicação na coordenação para a aplicação de Salvaguardas pelo bloco poderia ser visto como um sinal importante de que as economias estariam dispostas a se aproximarem, de fato.

Finalmente, infere-se que as iniciativas acerca da aplicação de Salvaguarda para determinado setor econômico do membro de um PIER fornecem, em verdade, indicativos relevantes acerca do real grau de integração das cadeias produtivas dos constituintes do bloco, podendo sim ser consideradas como mais um aspecto na medição do sucesso das iniciativas integracionistas. A aplicação individual ou pelo bloco, a exclusão dos membros do cumprimento das restrições impostas pela medida e a utilização dos dados econômicos dos demais membros dependem, ampla e fundamentalmente, do nível de integração alcançado pelos países.

\section{REFERÊNCIAS BIBLIOGRÁFICAS}

BALASSA, Bella. Teoria da integração econômica. 2. ed. Portugal: Clássica, 1972.

BARRAL, Welber Oliveira. Dumping e comércio internacional: a regulamentação antidumping após a Rodada Uruguai. Rio de Janeiro: Forense, 2000.

BENKE, Rafael. Antidumping e antitruste: na busca do antídoto contra a confusão. Revista de Direito Internacional e Econômico, Síntese/INCE, Porto Alegre, v. I, n. 4, jul./set. 2003.

BIELSCHOWSKY, Ralph. Cinquenta anos de pensamento na Cepal. São Paulo: Record, 2000. v. I.

BROGINI, Gilvan. Damiani. Medidas de salvaguarda e uniões aduaneiras. São Paulo: Aduaneiras, 2000. Juruá, 2002.

Medidas de salvaguarda. In: BARRAL, W. O. (org.). O Brasil e a OMC. 2. ed. Curitiba:

FONSECA, Pedro Paulo C. Defesas comerciais: um estudo jurídico das medidas legais internacionais de regulamentação do comércio multilateral e seus efeitos reais atuais. Revista de Direito Internacional e Econômico, Síntese/INCE, Porto Alegre, v. 2, n. 6, jan./mar. 2004.

GOYOS JÚNIOR, Durval Noronha et al. Tratado de defesa comercial: antidumping, compensatórias e salvaguardas. São Paulo: Observador Legal, 2003.

OLIVEIRA, Eveline. Medidas de salvaguarda. Revista Ambito Jurídico, Rio Grande do Sul, n. 47, 2007. Disponível em: <http://www.ambito-juridico.com.br/site/index.php?n_link=revista_artigos_ leitura\&artigo_id=2605>. 
Adriana S. Benatti - Cadernos PROLAM/USP ( Ano 7 - Vol. 2 - 2008) p. 113-126

PINHEIRO, Silvia; GUEDES, Josefina. Salvaguardas no comércio internacional. In: CASELLA, Paulo Borba; MERCADANTE, Araminta Azevedo (coord.). Guerra comercial ou integração mundial pelo comércio? A OMC e o Brasil. São Paulo: LTr, 1998.

PIRES, Adilson Rodrigues. Práticas abusivas no comércio internacional. Rio de Janeiro: Forense, 2001.

THORSTENSEN, Vera. Organização Mundial do Comércio. As regras do comércio internacional e a nova rodada de negociações multilaterais. 2. ed. São Paulo: Aduaneiras, 2003.

\section{Websites consultados:}

www.wto.org.br

www.mdic.gov.br

www.ambito-juridico.com.br 